DOI: $10.5902 / 198346592455$

\title{
ASSÉDIO MORAL NO TRABALHO: UM ESTUDO EXPLORATÓRIO NO MUNICÍPIO DE FORTALEZA - CEARÁ
}

\author{
MORAL HARASSMENT AT WORK: AN \\ EXPLORATORY STUDY IN FORTALEZA CITY
}

Recebido 05/01/2011

Aceito $02 / 05 / 2012$

Samira Daiha Benevides ${ }^{1}$

Fátima Regina Ney Matos ${ }^{2}$

Nemias Cardoso Figueiredo ${ }^{3}$

Kátia Lene de Araújo Lopes ${ }^{4}$

\section{RESUMO}

Pessoas assediadas estão ousando se expressar e denunciar as práticas abusivas de que são vítimas no ambiente de trabalho, assim, o objetivo deste artigo é apresentar a incidência dos casos de assédio moral no município de Fortaleza - Ceará, utilizando o banco de dados de queixas registradas pelas vítimas na Delegacia Regional do Trabalho, no período de janeiro de 2008 a dezembro de 2009. No referencial teórico conceitua-se o assédio moral, suas manifestações e aspectos legais, bem como as estruturas psíquicas de defesa do trabalhador. Foi feita uma pesquisa exploratória com a utilização de dados secundários, obtidos no Núcleo de Combate a Discriminação por meio do relatório mensal das denúncias de Assédio Moral, elaborado pela Comissão Regional de Igualdade de Oportunidades de Gênero, Raça e Etnia, de Pessoas com Deficiência e de Combate à Discriminação. Os resultados estão demonstrados por meio de gráficos que apontam o tipo de discriminação por assédio moral, por perfil profissional, sexo e idade do reclamante. Pode-se concluir que há discriminação em várias áreas, gerando, muitas vezes, comportamentos indesejáveis e condutas abusivas, degradando o clima de trabalho e reduzindo a produtividade.

Palavras-chave: Assédio moral; Discriminação; Estratégias defensivas; Clima organizacional; Produtividade

${ }^{1}$ Especialista em Estratégia e Gestão Empresarial pela Universidade Estadual do Ceará. E-mail: samirabenevides@hotmail.com

${ }^{2}$ Doutora em Administração pela Universidade Federal de Pernambuco, mestre em administração pela Universidade Estadual do Ceará e graduada em psicologia pela Universidade Federal do Ceará. Professora adjunta do Programa de Pós-Graduação em Administração da Universidade de Fortaleza (UNIFOR). E-mail: fneymatos@unifor.br

${ }^{3}$ Especialista em Estratégia e Gestão Empresarial. E-mail: nemihel@hotmail.com

${ }^{4}$ Mestre em Administração pela Universidade Estadual do Ceará, professora da Faculdade de Tecnologia Lourenço Filho. E-mail: katialene@gmail.com 


\section{ABSTRACT}

The objective of this article is to present the incidence of the cases of moral harassment in Fortaleza city using the data base of complaints registered for the victims in the Delegacia Regional do Trabalho in the period of January of 2008 the December of 2009. The literature review is based on the moral harassment, its legal manifestations, as well as the psychic structures of defense of the worker. A exploratory research with the use of secondary data was made in the Nucleus of Combat was become fullfilled the Discrimination through the monthly report of the denunciations of moral harassment elaborated by the Regional Commission of Equality of Chances of Gender, Race and ethnic group, of People with Deficiency and Combat to the Discrimination. The results had been demonstrated through graphs that had evaluated the type of discrimination for moral harassment, for professional profile, for sex and age of the plaintiff. The workers had more passed not to accept offences and behaviors that offend its dignity, demanding to be respected It can be concluded that still it has discrimination in some areas, generating many times behaviors undesirable and abusive behaviors, degrading the work climate and reducing the productivity.

Keywords: Moral harassment; Discrimination; Defensive strategies; Organizational climate; Productivity

\section{INTRODUÇÃO}

As organizações são "unidades sociais" que estão presentes em diferentes momentos e em formas diversas na vida cotidiana e, embora não sejam uma invenção recente, permeiam todo o tecido da sociedade moderna. Etzioni (1980, p. 9) as define como "unidades sociais (ou agrupamentos humanos) intencionalmente construídas e reconstruídas, a fim de atingir objetivos específicos".

Como qualquer agrupamento humano, as organizações não são homogêneas. Em seu interior, formam-se e desenvolvem-se diversos subgrupos que interferem na equação do poder.

Em razão das preferências e aversões individuais, formam-se na empresa, grupos, estados mentais favoráveis ou desfavoráveis aos objetivos, práticas, diretrizes, ordens suscitando os diferentes matizes de lealdade, deslealdade, hostilidade nas relações de trabalho (GUERREIRO RAMOS, 1983, p. 10).

Assim, na vida organizacional surgem relações de poder e de dominação que ocorrem apenas nas inter-relações humanas. Como o poder não existe em si e só se estabelece se duas partes integram-se pelo menos temporariamente, num conjunto organizado (CROZIER, 1983), o estudo do poder está relacionado ao assédio moral que um indivíduo exerce sobre o outro como prática nas relações de trabalho.

As relações de poder tornaram-se mais e mais sofisticadas após a Revolução Industrial, que gerou uma mudança radical na organização do trabalho, até então concentrado em oficinas, reunidas em corporações, de acordo com o ofício. Pela primeira vez, grandes quantidades de indivíduos foram reunidas em um mesmo ambiente, e esse fato tornou imprescindível "organizar, subdividir, disciplinar e supervisionar o trabalho de dezenas de pessoas sem qualificações específicas" (CLEGG, 1996, p.51).

Desde então, pode-se considerar que a manifestação do poder estabelece "relações sistematicamente assimétricas [...], pois indivíduos ou grupos particulares possuem um poder de maneira estável, de tal modo que excluem outros indivíduos ou grupos, não importando a base sobre a qual esta exclusão é levada a efeito" (THOMPSON, 1995, p.199).

Muitas vezes, esta exclusão está intimamente relacionada às situações de assédio moral, ou seja, aquelas situações que minam as forças e que podem prejudicar seriamente o 
indivíduo, constituindo-se em verdadeiros assassinatos psíquicos, porém apresentam-se como uma violência indireta, em relação a qual, sob o pretexto da tolerância, pode tornar o grupo de trabalho complacente, indiferente e omisso (FREITAS, 2001).

A violência perversa deve ser distinguida do abuso de poder direto ou da tirania. $A$ tirania é uma maneira de obter o poder pela força. A opressão nela é visível: um se submete porque o outro tem visivelmente o poder. No abuso de poder direto, o objetivo é simplesmente dominar (HIRIGOYEN, 2009, p. 129).

De acordo com Hirigoyen (2009), o abuso do poder dos chefes sempre existiu, mas atualmente fica muitas vezes disfarçado. Os diretores falam em autonomia e espírito de iniciativa a seus empregados, mas só exigem deles submissão e obediência. Os assalariados produzem porque estão obcecados com as ameaças referentes à sobrevivência da empresa, ou por estarem sendo continuamente cobrados.

Geralmente, o assédio moral começa pelo abuso de poder, qualquer que seja a sua base de sustentação, segue por um abuso narcísico, no qual o outro perde a autoestima e pode chegar, às vezes, ao abuso sexual. Hirigoyen (2009, p. 90) aponta que não existe apenas a busca do poder há, sobretudo, um enorme prazer em usar o outro como objeto. $\mathrm{O}$ agressor procura reduzir o outro a uma posição de impotência para, em seguida, tentar destruí-lo, com total impunidade.

Segundo Margarida Barreto, médica especialista no trato dos efeitos do assédio moral, e pesquisadora do Departamento de Psicologia da Pontifícia Universidade Católica de São Paulo (PUC-SP), o problema hoje pode ser considerado uma questão de saúde pública (CARMO, 2009). Tendo se dedicado ao estudo minucioso do assunto, sua pesquisa resultou em números assombrosos na vida laboral. Com um resumido quadro sinótico, intitulado "Raio $X$ da Violência Moral", a autora expôs o resultado de sua investigação. Dentre 42.000 trabalhadores em todo o País, 10.000 afirmaram haver experimentado, repetidas vezes, situações intencionalmente provocadas, como: humilhação, embaraço e coação. Ou seja, reconheceram prontamente a tipicidade da conduta descrita pelo assédio moral, na seguinte proporção: $90 \%$ reconhecem como assediador o chefe; $6 \%$, os colegas de trabalho; e 1,5\% sofrem assédio de seus subordinados (CARMO, 2009).

\section{PROBLEMA DE PESQUISA E OBJETIVO}

Diante do cenário acima exposto, que mostra um grande número de casos de assédio moral acontecendo atualmente nas organizações, resultando em implicações na vida profissional e familiar dos colaboradores, bem como na convivência social, foi formulado o seguinte problema de pesquisa: qual a incidência do assédio moral no município de Fortaleza - Ceará com base no banco de dados da Delegacia Regional do Trabalho?

Assim, o objetivo deste artigo é apresentar a incidência dos casos de assédio moral no município de Fortaleza, utilizando o banco de dados de queixas registradas pelas vítimas na Delegacia Regional do Trabalho, no período de janeiro de 2008 a dezembro de 2009.

A violência moral nas empresas tem contornos sutis que se manifestam por meio da coação, da humilhação e dos constrangimentos, que nem sempre são percebidos pelas vítimas como um ato de violência. $O$ fenômeno do assédio moral no ambiente de trabalho é um assunto de grande relevância jurídica e social, tendo em vista a frequência com que ocorre, e os imensos prejuízos causados às vítimas. $\mathrm{O}$ assédio moral, como qualquer conduta abusiva, de modo repetitivo, contra a dignidade ou integridade psíquica ou física de uma pessoa, ameaça seu emprego e/ou degrada o clima no ambiente de trabalho. 


\section{ASSÉDIO MORAL NAS ORGANIZAÇÕES}

A utilização do termo assédio moral no universo do trabalho é recente. Segundo Hirigoyen (2002), somente no começo da década de 1990, o assédio foi realmente reconhecido como um fenômeno destruidor do ambiente de trabalho.

Por assédio em local de trabalho, entende-se "qualquer conduta abusiva (gesto, palavra, comportamento, atitude...) que atente, por sua repetição ou sistematização, contra a dignidade ou à integridade psíquica ou física de uma pessoa, ameaçando seu emprego ou degradando o clima de trabalho" (HIRIGOYEN, 2002, p.17).

$\mathrm{O}$ assédio nasce como algo inofensivo e propaga-se insidiosamente. Em um primeiro momento, as pessoas envolvidas não se mostram ofendidas e levam na brincadeira desavenças e maus-tratos. Em seguida, os ataques se multiplicam e a vítima é seguidamente acuada, posta em situação de inferioridade, submetida a manobras hostis e degradantes durante um período maior. O assédio torna-se possível porque vem precedido de uma desvalorização da vítima pelo agressor, levando o ofendido a pensar que realmente merece o que está acontecendo (HIRIGOYEN, 2009).

Em relação à vítima, em princípio, ela não traz nenhuma patologia ou fraqueza psíquica. Geralmente, é o assédio que desencadeia a reação, e isso se torna possível porque é precedido de um processo de desqualificação, que é aceito em silêncio, muitas vezes com a cumplicidade do grupo de trabalho. No nosso dia a dia, não ousamos falar de perversidade; no entanto, as agressões reanimam um processo inconsciente de destruição psicológica, constituído de procedimentos hostis, evidentes ou escondidos, de um ou vários indivíduos sobre o outro, na forma de palavras insignificantes, alusões, sugestões e não ditos, que efetivamente podem desestabilizar alguém, ou mesmo destruí-lo, sem que os que o cercam intervenham (FREITAS, 2001).

Essa depreciação dá a justificativa a priori para a crueldade exercida contra a vítima, e a conduz a pensar que "merece o que está lhe acontecendo". Assim que o processo tem início, a vítima passa a ser estigmatizada: diz-se que ela é difícil de conviver, tem mau-caráter ou é louca - temperamental, desvairada, irresponsável (FREITAS, 2001).

O agressor pode engrandecer-se rebaixando o outro, sem culpa e sem sofrimento: trata-se da perversão moral. A perversidade não provém de um problema psiquiátrico, mas de uma racionalidade fria combinada a uma incapacidade de considerar os outros como seres humanos (FREITAS, 2001).

A lista de possibilidades de configuração do assédio moral é extensa, de forma que, não se manifesta apenas por ofensas verbais ou escritas. Olhares, suspiros e desprezos como respostas a indagações também podem ser caracterizados como assédio moral. Da mesma forma, podem caracterizar o assédio moral atos e mandados que envolvam ordens inócuas, tarefas desprovidas de qualquer utilidade prática, metas de produtividade impossíveis de serem alcançadas, enfim, formas de desprestígio que podem ser utilizadas pelo empregador ou seus prepostos. Além disso, na maioria das vezes, essas atitudes vêm acompanhadas do isolamento, já que os colegas, também temendo represálias, acabam se afastando da vítima, que fica cada vez mais isolada e fragilizada (MORAES, 2009).

O que favorece o assédio moral é, acima de tudo, o ambiente de trabalho no qual não existem regras internas, nem para os comportamentos nem para os métodos. Tudo parece permitido, o poder dos chefes não tem limites, assim como o que pedem aos subordinados (HIRIGOYEN, 2009).

Baseando-se nas pesquisas de Barreto (2000) e de Barreto e Salvador (2005) sobre o assédio moral no Brasil, assim como em uma série de considerações sobre seus aspectos jurídicos e políticos, nacionais e internacionais, pode-se apontar que o fenômeno, embora histórico, intensifica-se nas atuais mudanças do sistema produtivo e da gestão: "o modo como o trabalho está 
organizado e é gerido favorece relações violentas"; o imperativo da flexibilidade é relacionado à proliferação de "regras incertas, mutáveis, promessas não cumpridas, reconhecimentos negados, punições arbitrárias, exigências de submissão de uns e arrogância de outros" (FREITAS, HELOANI, BARRETO, 2008, p. 53).

O dia a dia nas organizações é permeado por disputas de poder e busca de oportunidades para aumentar as arenas de influência, não constituindo nenhuma surpresa o fato dos locais de trabalho não serem exatamente um clube de anjos. As pessoas mortais costumam lutar pelos seus interesses, e as organizações instigam essa luta, considerando que certa dose de competição e animosidade lhes é até benéfica (FREITAS, 2001).

\section{Aspectos legais do assédio moral}

Por tratar-se de uma situação relativamente nova para o mundo jurídico, a legislação ainda é bastante esparsa e falha, deixando uma série de dúvidas sobre qual a definição legal do assédio moral e suas consequências. Exceção à regra, a legislação trabalhista francesa é a mais clara, estabelecendo que nenhum funcionário poderá ser punido por ter sofrido o assédio moral, ou ainda, ter testemunhado ou relatado tais situações (MORAES, 2009).

Diante dessa realidade, a Justiça do Trabalho tem se posicionado independentemente da existência de leis específicas. Esclarece a Ministra Maria Cristina Irigoyen Peduzzi, do TST, que "a teoria do assédio moral se baseia no direito à dignidade, fundamento da República Federativa do Brasil, como prevê o artigo 1ำ, inciso III, da Constituição". Esclarece ainda a Ministra, que "é possível citar também o direito à saúde, mais especificamente à saúde mental, abrangida na proteção conferida pelo artigo 6으, e o direito à honra, previsto no artigo 5으, inciso $\mathrm{X}$, também da mesma Constituição" (MORAES, 2009, ).

O Ministro João Oreste Dalazen, também do Tribunal Superior do Trabalho (TST), esclarece que a caracterização do assédio moral se dá "pela violência psicológica extrema à qual uma pessoa é submetida por um chefe ou mesmo por um colega de trabalho". Entretanto, o Ministro ressalta que situações isoladas não se convertem em assédio moral, "é necessário haver uma perseguição sistemática". Por fim, ele ressalta que, a maioria dos casos é de reclamações contra assédios morais impostos por chefes hierárquicos a subordinados, aos quais submetem às situações de violência psicológica (BRASIL, 2002, p.5).

$\mathrm{O}$ assédio moral tem sido prática comum em empresas que são obrigadas a manter funcionários que, de alguma forma, possuem estabilidade provisória ou permanente, decorrente de lei ou ordem judicial. Como não podem demitir tais funcionários, as empresas utilizam-se desse artifício para tornar a vida do funcionário na empresa insuportável, de forma que este venha a pedir demissão (MORAES, 2009). A prática do assédio moral no trabalho também tem sido comum em empresas que implantam programas de demissão voluntária (PDV). O funcionário se nega a aderir ao programa e passa a ser vítima de perseguição.

Atualmente, tramitam, no Congresso Nacional, alguns projetos de lei com o objetivo de alterar a Consolidação das Leis do Trabalho (CLT) e o Código Penal com a introdução de artigos que definam e punam o assédio moral. O objetivo dos projetos é, acima de tudo, caracterizar o assédio moral, determinado quando uma ação no ambiente de trabalho ganha esses contornos (STADLER, 2008, p.71).

O Projeto de Lei no 2.369/2003 encontra-se pronto para entrar em pauta no Congresso Nacional e dispõe sobre o assédio moral, caracterizando-o não como crime, mas como ilícito trabalhista, podendo gerar o direito à indenização. Como o assédio moral no trabalho é uma 
realidade, a Justiça do Trabalho tem se posicionado antes mesmo da existência de leis específicas e podem-se identificar queixas dos empregados nos órgãos competentes.

A prática de assédio moral tem ensejado condenações à reparação de danos morais pelos Tribunais pátrios, independente de a legislação tratar especificamente do tema. Os tribunais já começaram a se manifestar sobre o tema, e aqui vale lembrar a força determinante da jurisprudência. Esta vem desenvolvendo a ideia de assédio moral sem previsão legal explícita e demonstrando preparo e sensibilidade na proteção dos direitos fundamentais dos trabalhadores, no combate a atitudes perversas que podem trazer danos à personalidade, à dignidade e à integridade psíquica do trabalhador (STADLER, 2008, p. 86).

\section{ESTRATÉGIAS PSÍQUICAS DE DEFESA DO TRABALHADOR}

Estudos como os de Antunes (2002), Gorz (2002) e Druck (1999) apontam para a importância da relação do homem com o trabalho, bem como para sua capacidade de adaptação e sua saúde psíquica.

Segundo Hirigoyen (2009), em um grupo, é normal que os conflitos se manifestem. Um comentário ferino em um momento de irritação ou mau humor não é significativo se vier acompanhado de um pedido de desculpas. É a repetição dos vexames, das humilhações, sem qualquer esforço de abrandá-las, que torna o fenômeno destruidor.

A prática do assédio moral é uma situação real que expõe o trabalhador a uma série de riscos, tanto físicos quanto psíquicos. Segundo Freitas (2001), infelizmente, essas práticas ainda encontram suporte no preconceito, na desinformação e na mentalidade machista, todos impressos nos valores sociais. A pessoa agredida acaba sendo levada a acreditar que é sua reputação, e não a do agressor, que ficará manchada, que é ela que deve envergonhar-se e que será ela o objeto de censura e de desaprovação social.

É sabido que devido à redução de postos de trabalho, ao risco constante de perda do emprego, à ênfase na produtividade e à maior competitividade, as relações de trabalho se tornaram estressantes, fragilizadas, exigindo das pessoas muito mais esforço e desempenho nas suas funções. O nível hierárquico superior exige que seus subordinados se superem, impondo metas impossíveis de serem alcançadas no prazo estabelecido.

Mendes e Cruz (2004) afirmam que não é o trabalho que causa a doença mental, mas que ele pode ser um desencadeante. Situações nas quais o trabalhador é assediado moralmente são tipicamente desencadeadoras de doenças. Dejours, Abdoucheli e Jayet (1994) indicam que a carga psíquica de trabalho e seu manejo estão diretamente relacionados ao caráter qualitativo e dinâmico subjetivo da experiência vivenciada frente às pressões ou exigências do trabalho cotidiano. Aspectos culturais da organização e a visão desta sobre os papéis esperados e desempenhados pelos funcionários, a importância de uma estrutura que comporte e corresponda à necessidade dos profissionais que dela fazem parte, assim como liberdade de ação e produção, são fundamentais não apenas para a motivação e o crescimento profissional do trabalhador, mas também para o sucesso da empresa.

Segundo Moreira (2008), a pressão da chefia pelo cumprimento de prazos, metas e objetivos do negócio faz considerar que seus subordinados podem fazer mais do que realmente podem. As constantes humilhações, a exposição do trabalhador ao ridículo, a supervisão excessiva, as críticas cegas, o empobrecimento das tarefas, a sonegação de informações e as repetidas perseguições são notas características do assédio moral, cuja prática está relacionada geralmente a uma relação de poder. 
Segundo Moreira (2008), um chefe tirano projeta em suas vítimas as próprias fraquezas morais e profissionais, sugerindo que elas superem a falsa percepção do modo como as coisas estão ocorrendo, encarando apenas como uma forma dura de chefiar ou, ainda, de uma reorganização empresarial.

Quando adoece por causa do assédio moral no trabalho, o empregado, muitas vezes, não sabe identificar tal doença porque muitos não conhecem seu próprio corpo e só sabem que estão doentes quando sentem alguma dor. Dejours (1992) dá o nome a essas estratégias defensivas de ideologia da vergonha e ideologia defensiva. A ideologia da vergonha tem como objetivo manter à distância a doença, o sofrimento ou tudo o que lembre direta ou indiretamente o adoecer.

A ideologia defensiva tem em primeiro lugar como objetivo mascarar, conter e ocultar
ansiedade particularmente grave. Em segundo lugar é em nível da ideologia defensiva,
enquanto mecanismo de defesa elaborado por um grupo social particular, que devemos
procurar uma especificidade. Em terceiro lugar, o que caracteriza uma ideologia defensiva
é o fato de ela ser dirigida não contra uma angústia proveniente de conflitos intrapsíquicos
de natureza mental, e sim ser destinada a lutar contra um perigo e um risco real (DEJOURS,
1992, p. 35-36).

De acordo com Dejours (1992, p. 38), "a ideologia defensiva, para ser funcional, deve ser dotada de uma certa coerência. $O$ que supõe certos arranjos relativamente rígidos com a realidade. A ideologia defensiva tem um caráter vital, fundamental, necessário". Essa mesma ideologia se torna obrigatória quando o profissional se afasta de seu grupo social, ficando, assim, indefeso diante da realidade. Quando o indivíduo compartilha com seu grupo, ele age junto aos conflitos de ordem mental, garantindo um domínio mínimo da realidade perigosa.

Dejours (2005) aponta para a importância do reconhecimento na vida do trabalhador, mostrando que, ao contrário do que muitos pensam, o reconhecimento reivindicado é fator decisivo na dinâmica da mobilização subjetiva da inteligência e da personalidade no trabalho. Quando não há reconhecimento pela qualidade do serviço prestado, todos os esforços são em vão, o que pode provocar uma desconstrução na identidade do trabalhador.

\section{PROCEDIMENTOS METODOLÓGICOS}

Pesquisa exploratória é toda pesquisa que busca constatar algo num organismo ou num fenômeno. Os estudos exploratórios, na visão de Cooper e Schindler (2003), tendem a gerar estruturas com o objetivo de desenvolver hipóteses ou questões para pesquisa adicional. É útil quando a área de investigação é nova, e é necessária a exploração para conhecer algo sobre o problema enfrentado pelo pesquisador. A fim de atingir o objetivo proposto, foi realizada uma revisão bibliográfica em livros, periódicos e sites que abordam o tema assédio moral, suas implicações e consequências na vida profissional do trabalhador.

Godoy(1995)consideraquea abordagem qualitativa oferecetrês diferentes possibilidades de pesquisa: a pesquisa documental, o estudo de caso e a etnografia. Os documentos constituem uma fonte não reativa, pois as informações neles contidas permanecem as mesmas após longos períodos de tempo (BAILEY, 1982). Documentos incluem materiais escritos (jornais, revistas, diários, obras literárias, científicas e técnicas, cartas, memorandos, relatórios), estatísticas (que produzem um registro ordenado e regular de vários aspectos da vida de determinada sociedade) e elementos iconográficos (sinais, grafismos, imagens, fotografias, filmes). Nesta pesquisa, os documentos utilizados podem ser considerados material estatístico. 
Foram coletados dados em fontes secundárias, pois as pessoas assediadas não estavam presentes por ocasião da pesquisa (GODOY, 1995). As informações foram obtidas na Delegacia Regional do Trabalho. Inicialmente foi enviado um ofício protocolado para o Superintendente do Ministério do Trabalho e Emprego, solicitando o acesso ao banco de dados referentes ao objeto dessa pesquisa. Após a permissão do Superintendente, os dados foram acessados no Núcleo de Combate a Discriminação, por meio do relatório mensal das denúncias de Assédio Moral elaborado pela Comissão Regional de Igualdade de Oportunidades de Gênero, Raça e Etnia, de Pessoas com Deficiência e de Combate à Discriminação, enviado mensalmente ao Ministério do Trabalho em Brasília, onde os dados são compilados em nível nacional. Não foi permitido o acesso às fichas preenchidas que deram origem a esse relatório.

O universo da pesquisa foi formado por 678 vítimas de assédio moral com queixa registrada na Delegacia Regional do Trabalho (DRT), sendo 366 no ano de 2008, e 312, em 2009.

\section{RESULTADOS}

O reclamante/suposto assediado caso queira formalizar sua reclamação, solicita-lhe o preenchimento dos dados na ficha pelo servidor mediador, após a verificação da real necessidade de comprovação da reclamação. Na ficha, são preenchidos os dados pessoais e profissionais do reclamante, além do setor de atividade econômica no qual ele trabalha, constando, ainda, os tipos de discriminação, tais como: em razão das relações de gênero; da diferença de remuneração; do assédio moral; do estado civil; de revista íntima; de gravidez; de contratação para os cargos de chefia; de discriminação em razão da raça/cor ou etnia, em razão da orientação sexual, em razão de assédio moral; da idade; do estado de saúde (se portador do Vírus da Imunodeficiência Humana - HIV e/ou Síndrome da Imunodeficiência Adquirida - AIDS, etc.); e em razão de demais fatores (sociais, políticos, econômicos, culturais e outros).

Em outro campo da ficha, são descritos os dados do atendimento, especificando o motivo da discriminação como indicador qualitativo, além do tipo de atendimento, se denúncia, reclamação, sugestão, elogio, informações, solicitações e/ou dúvidas.

Depois de formalizada a denúncia, o Núcleo de Combate a Discriminação envia convite por escrito, com hora e data marcadas, solicitando a presença do empregado e empregador. O convite menciona o assunto relativo à discriminação no ambiente de trabalho, envolvendo o trabalhador de seu quadro funcional, constando, ainda, que um dos objetivos dessa Superintendência é o combate a todas as formas de discriminação que afetem a dignidade dos trabalhadores e a violação dos direitos de personalidade, conforme Projeto de Lei no 2.369/2003.

No dia e hora marcados para a mediação, sentam, em uma mesa redonda, o empregado reclamante, o empregador e a mediadora. Ouvem-se as partes, a versão de cada um, e uma das partes dá sugestões que poderiam melhorar o ambiente de trabalho. Tudo é registrado em Ata de Mediação, impressa em três vias.

Conforme a servidora mediadora, o empregador não é obrigado a comparecer à mediação, porém praticamente todos comparecem, acredita a mediadora, por medo de alguma represália ou maior fiscalização por parte do Órgão,. No entanto, conforme a servidora, ainda não existe uma fiscalização para verificar se realmente as sugestões de melhorias feitas nos acordos são cumpridas, ou seja, o Núcleo de Combate à Discriminação não tem dados que comprovem o verdadeiro cumprimento desses acordos. 


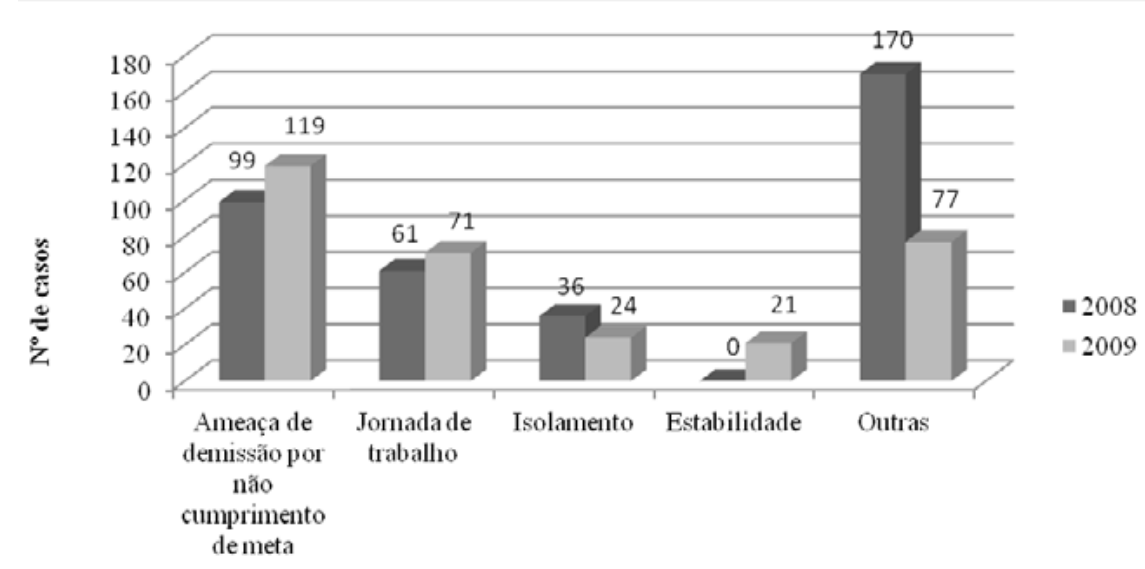

Tipos de discriminação

Figura 1: Casos de assédio moral registrados na DRT, nos anos de 2008 e 2009, de acordo com o tipo de discriminação. Fonte: DRT, 2010

Na figura 1, acima, pode-se observar a representação gráfica de alguns dados coletados na DRT, dos anos de 2008 e 2009, quanto a algumas formas de discriminação por assédio moral.

Hirigoyen (2002) considera como assédio em local de trabalho qualquer conduta abusiva (gesto, palavra, comportamento, atitude...). Pode-se observar que as principais causas de discriminação são "outras" (247 casos) e "ameaça de demissão por não cumprimento de meta" (218 casos), o que corrobora os achados de Moreira (2008). É importante salientar que, na coluna 'outras', não foi especificado nas fichas o tipo de reclamação.

Verifica-se que, do ano de 2008 para 2009, houve um aumento $20,20 \%$ de reclamações quanto à ameaça por não cumprimento de meta; já para jornada de trabalho, ocorreu aumento de $16,40 \%$. Com a exigência do cumprimento das metas organizacionais, é possível que indivíduos em cargo de chefia confundam rigor profissional com comportamentos disfuncionais, que caracterizam o assédio moral, visto que Barreto apud Carmo (2009) identificou que $90 \%$ das vítimas de assédio moral reconhecem o chefe como assediador.

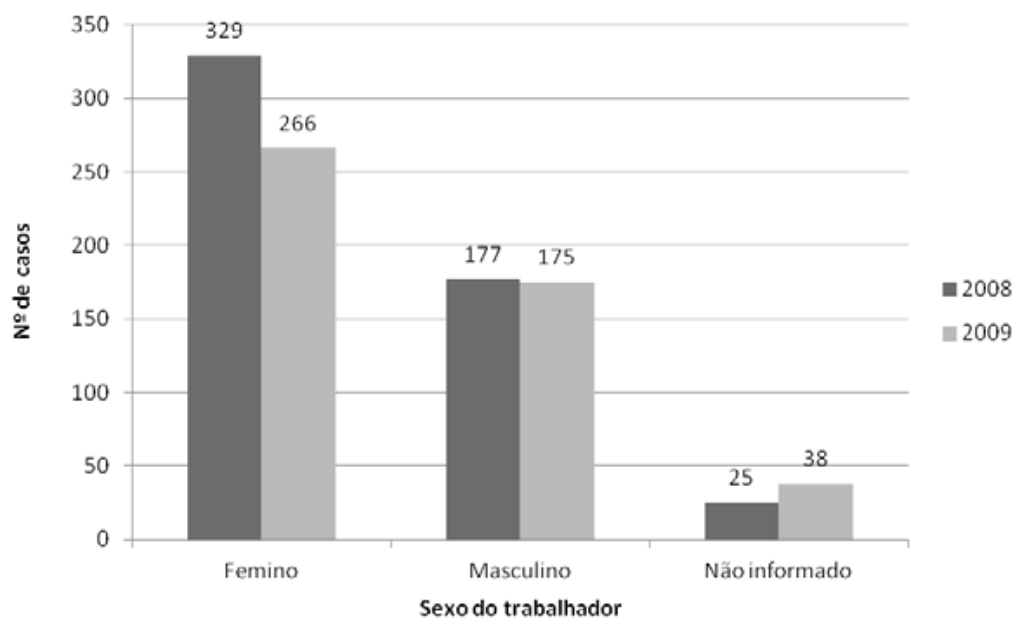

Figura 2: Casos de assédio moral registrados na DRT, nos anos de 2008 e 2009, em relação ao gênero. Fonte: DRT, 2010 
Na figura 2, podem-se observar os casos de assédio moral relacionados ao gênero. As mulheres registram significativamente mais reclamações como vítimas de assédio moral, o que corrobora a literatura sobre o assunto (BARRETO, 2008 FREITAS, 2001).

De 2008 para 2009, houve uma diminuição do número de reclamações feitas por mulheres, passando de $62 \%$ para $56 \%$ do total. A diferença na quantidade de reclamações feitas por trabalhadores do sexo masculino não foi tão significativa de um ano para o outro, levando-se em conta que, em 2008, representou 33\% e, em 2009, 37\%.

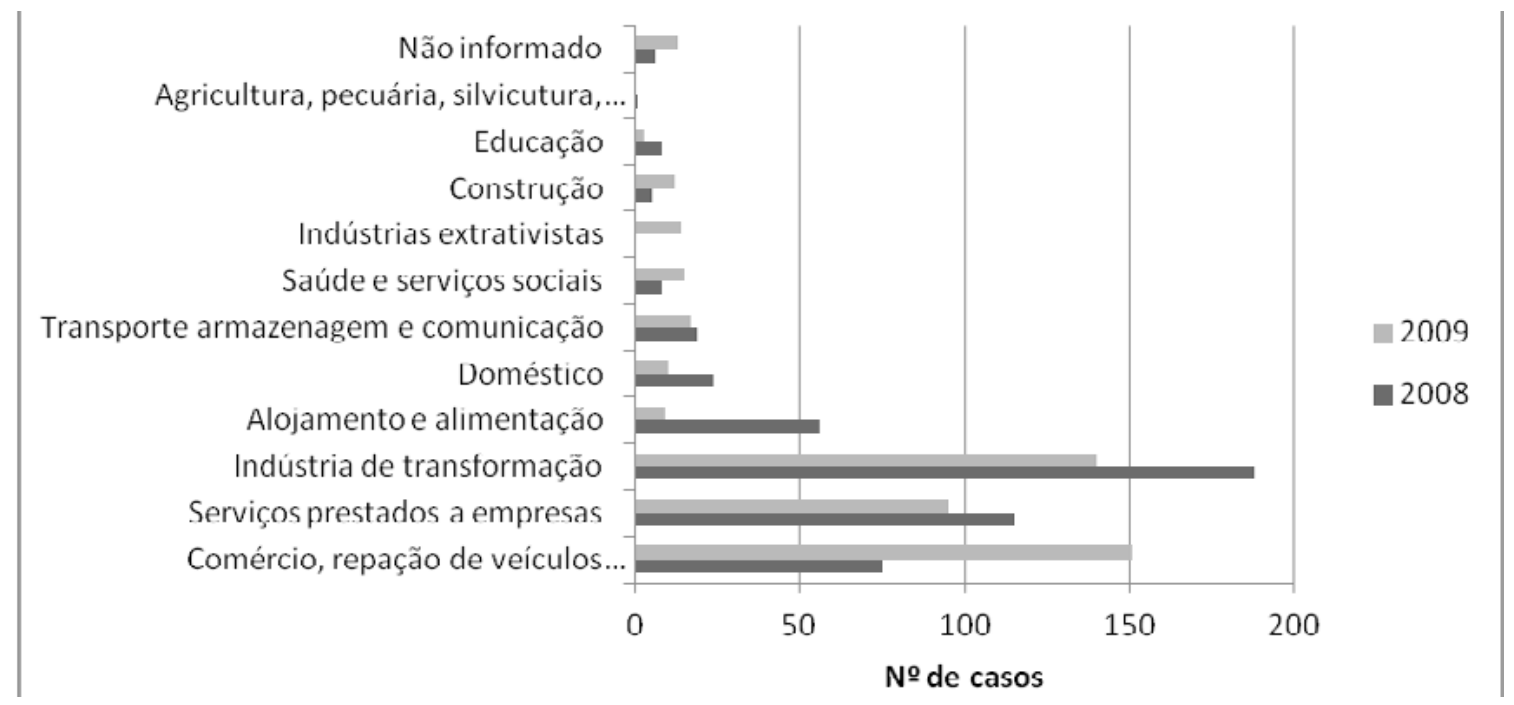

Figura 3: Casos de assédio moral registrados na DRT nos anos de 2008 e 2009 de acordo com o setor de atividade. Fonte: DRT, 2010

Na figura 3, podem-se observar três setores de atividades que se sobressaíram em relação aos demais, sendo eles: comércio e reparação de veículos automotores; objetos pessoais e domésticos; indústria de transformação e serviços prestados às empresas; atividades imobiliárias e aluguéis.

Em 2008, o setor da indústria de transformação foi o que mais obteve reclamações, representando $37 \%$ do total, seguido do setor de serviços prestados às empresas, atividades imobiliárias e aluguéis, com $23 \%$. Já no ano de 2009, o setor que prestou mais denúncias foi o de comércio e reparação de veículos automotores, objetos pessoais e domésticos, com $32 \%$, seguido por $29 \%$ de denúncias do setor de transformação.



Figura 4: Casos de assédio moral registrados na DRT, nos anos de 2008 e 2009, de acordo com a faixa etária do trabalhador. Fonte: DRT, 2010 
De acordo com a figura 4, a faixa etária de trabalhadores entre 26 e 35 anos representou $42 \%$ do total das reclamações de 2008; já em 2009, representou $27 \%$, seguida da faixa etária de 18 a 25 anos, com $40 \%$ e $4 \%$, respectivamente.

Pode-se observar que, do ano de 2008 para 2009, houve um aumento significativo de $121 \%$ de reclamações de pessoas da faixa etária de 36 a 45 anos; no entanto também foi observado aumento de $100 \%$ nas pessoas que não informaram suas idades.

\section{CONSIDERAÇÕES FINAIS}

Com base no banco de dados dos anos de 2008 e 2009, obtidos na Delegacia Regional do Trabalho, no município de Fortaleza - Ceará, pode-se verificar que há incidência significativa do assédio moral, e que este pode ser considerado um assunto que deve ser discutido e aprofundado no meio empresarial e na sociedade, com isenção de ânimo e muita objetividade, para que não interfira negativamente nos resultados da organização.

Com o levantamento das denúncias de acordo com o tipo de discriminação, a ofensa verbal foi a que mais se destacou nos dois anos, seguida pela ameaça de demissão por não cumprimento de metas e da jornada de trabalho, embora outros tipos de discriminação não tenham sido informados, principalmente no ano de 2008, com elevado percentual.

Quanto ao segmento econômico, os três perfis profissionais dos trabalhadores ou setores de atividade que obtiveram maior representatividade nos anos pesquisados (2008 e 2009) foram o comércio e a reparação de veículos automotores, objetos pessoais e domésticos; os serviços prestados às empresas e às indústrias da transformação.

Quanto ao perfil do trabalhador, em relação ao gênero, as mulheres foram as que mais registraram reclamações na DRT, como vítimas de assédio moral. Em relação à idade, a faixa etária que mais se destacou foi a de 26 a 35 anos, seguida da faixa etária de 18 a 25 anos.

O objetivo deste trabalho foi apresentar a incidência dos casos de assédio moral no município de Fortaleza - Ceará, utilizando o banco de dados de queixas registradas pelas vítimas na Delegacia Regional do Trabalho, no período de janeiro de 2008 a dezembro de 2009. Assim, pode-se concluir, de acordo com o banco de dados da Delegacia Regional do Trabalho, que a incidência do assédio moral no município de Fortaleza ainda é elevada em relação a, pelo menos, quatro aspectos. Quanto ao tipo de discriminação de assédio moral, apresentando maiores índices de reclamações com relação a ameaças de demissão por não cumprimento de metas, assim como a jornada de trabalho; quanto ao segmento econômico, com relação ao comércio e a reparação de veículos automotores, objetos pessoais e domésticos; quanto ao sexo, mostrando que as mulheres são as que mais registram reclamações como vítimas de assédio moral; e, com relação à faixa etária, a que mais se destacou foi a de 26 a 35 anos.

È necessário que novos trabalhos sejam realizados sobre o tema em questão, e que seja verificado se o órgão responsável realmente fiscaliza os acordos firmados e as recomendações de melhorias sugeridas pelo reclamante e pelo reclamado.

Como ação preventiva, sugere-se a realização de seminários, palestras e outras atividades voltadas para a discussão e sensibilização sobre tais práticas abusivas, para que as mesmas sejam erradicadas do ambiente de trabalho e deixem de ser fator de risco psicossocial, capaz de provocar danos à saúde do trabalhador assediado. 


\section{REFERÊNCIAS}

ANTUNES, R. Os sentidos do trabalho - Ensaios sobre a afirmação e a negação do trabalho. 6a Ed. São Paulo: Boitempo, 2002.

BAILEY, K. D. Methods of social research. 2. Ed. New York: Free Press, 1982.

BARRETO, M. Assédio moral: risco não visível no ambiente de trabalho. Informe ENSP. Rio de Janeiro: Agência Fiocruz de Notícias, 2008.

Assédio moral: ato deliberado de humilhação ou uma política da empresa para livrar-se de trabalhadores indesejados. Ser Médico. Ano V, n. 20, p. 28-31, 2002.

Uma jornada de humilhação. São Paulo: FAPESP: PUC, 2000.

BARRETO, M.; SALVADOR, L. Assédio moral: a necessidade de romper-se com o silêncio. Jus Vigilantibus, março 2005

BRASIL. Projeto de Lei no 2.369/2003.

BRASIL. Constituição Federal de 1988. 8a ed. São Paulo: Editora Juarez de Oliveira, 2002.

CARMO, S.J. de O. A inveja como fundamento e motivação do "delito" de assédio moral. Disponível em: www.monografias.com. Acesso em: 23/08/2009.

CLEGG, S. Poder, linguagem e ação nas organizações. In: CHANLAT, J-F. (Org.). 0 indivíduo nas organizações - dimensões esquecidas. São Paulo: Atlas, 1996.

CROZIER, M. A sociedade bloqueada. Brasília, DF: Editora da UnB, 1983.

DEJOURS, C. A banalização da injustiça social. 6. a ed. - Rio de Janeiro: Editora FGV, 2005.

A Loucura do Trabalho: estudo de psicopatologia do trabalho. $5^{a}$ ed. São Paulo: Cortez, 1992.

ABDOUCHELI, E.; JAYET, C. Psicodinâmica do Trabalho. São Paulo: Atlas, 1994.

DRUCK, Maria da Graça. Terceirização: (Des) fordizando a Fábrica. São Paulo: Boitempo, 1999.

ETZIONI, A. Organizações modernas. 6ạ Ed. São Paulo: Livraria Pioneira Editora, 1980.

FREITAS, M.E.de. Assédio moral e assédio sexual: faces do poder perverso nas organizações. RAE - Revista de Administração de Empresas, Relações de Trabalho, v.41, n.2, p. 8-19, Abr./Jun. 2001.

FREITAS, M.E. de, HELOANI, R., BARRETO, M. Assédio Moral no trabalho. São Paulo: Cengage Leaning, 2008.

GODOY, A. S. Pesquisa qualitativa - Tipos fundamentais. Revista de Administração de Empresas. São Paulo, v. 35, n. 3, p. 20-29, mai./ jun. 1995.

GORZ, A. Crítica da Divisão do Trabalho. 3a ed. São Paulo: Martins Fontes, 2002.

GUERREIRO RAMOS, A. Administração e contexto brasileiro: esboço de uma teoria geral da administração. Rio de Janeiro: Editora FGV, 1983.

HIRIGOYEN, M. F. Assédio Moral - A violência perversa no cotidiano. Rio de Janeiro, Editora Bertrand Brasil, 2009.

Mal-Estar no Trabalho - Redefinindo - Assédio Moral. Rio de Janeiro, Editora Bertrand Brasil, 2002.

MENDES, A. M.; CRUZ, R. M. Trabalho e saúde no contexto organizacional: vicissitudes teóricas. In: TAMAYO, A. (org.). Cultura e saúde nas organizações. São Paulo: Artmed, 2004.

MORAES, D. Assédio Moral: uma nova tormenta para as empresas. Almeida Moraes e Rotta Advogados. Disponível em: amradvogados.com/assediomoral.aspx. Acesso em: 23/05/2010. 
MOREIRA, B.L. Assédio Moral. Artigos.

Fênix Editora. Disponível em: http://www.

fenixeditora.com.br Acesso em: 26/07/2008.

STADLER, D. de F. Assédio Moral: uma análise da teoria do abuso de direito aplicada ao poder do empregador. São Paulo, Editora LTr, 2008.

THOMPSON, J. B. Ideologia e Cultura Moderna

- Teoria social crítica na era dos meios de comunicação de massa. 5a ed. Petrópolis: Vozes, 1995. 